\title{
Head and neck cancers: Safely preserving the talk
}

Radiotherapy (RT) is an important modality in the treatment of head and neck malignancies. Although early Stages I and II head and neck cancer patients are usually managed with definitive RT or surgery alone, patients with more-advanced Stage III cancers need the use of concurrent chemotherapy along with radiation.

During the past two decades, RT has been combined with chemotherapy for advanced-stage head and neck cancer of several sites, especially in the concomitant setting to yield increased control rates and improved survival. ${ }^{[1]}$ Furthermore, there is emerging evidence that compared with conventional fractionated RT (one fraction/day at the rate of five fractions/ week), altered fractionation schedules can increase the tumor cell kill. In a multicentric study, the 5-year actuarial rate of loco regional control was $42 \%$ in the accelerated group versus $30 \%$ in the conventional group (hazard ratio [HR]: $0.63,95 \%$ confidence interval $[\mathrm{CI}]: 0.49-0.83 ; P=0.004) .{ }^{[2]}$ Other active areas of research in head and neck cancers include human papillomavirus (HPV) associated cancers and genetic studies, including cytochrome P450 alterations. ${ }^{[3]}$

The near exponential rise of the incidence of HPV-related oropharyngeal squamous cell carcinomas presents the practitioner with a "novel" head and neck cancer patient. This patient is radically different from those with the traditional risk factors that most of our oncology community is accustomed to. This patient is younger and lacks traditional risk factors. The aim of treatment in these cases is to maintain or improve current excellent cure rates, while lessening treatment related side effects. ${ }^{[4]}$

A seminal aspect of cancer management in head and neck is organ preservation. Organ preservation strategies in head and neck cancers have gained considerable attention and interest amidst oncologists, patients and even lay media. All these issues are covered in original articles or reviews in the present issue of the journal.

Ever since the publication of the landmark Veterans Affairs trail, organ preservation using chemoradiation in head and neck cancer has emerged as strong alternative to the traditional approach of surgery. ${ }^{[5]}$ This and other trials that followed clearly established the long-term safety of the approach of organ preservation using integration of chemotherapy and radiation..$^{[5,6]}$ In the meta-analysis of chemotherapy in head and neck cancer analysis the 5-year absolute benefits associated with the concomitant chemotherapy was $8.9 \%, 8.1 \%, 5.4 \%$ and $4 \%$ for oral cavity, oropharynx, larynx and hypopharynx tumors, respectively. ${ }^{[7]}$

The principles of organ preserving approach are simple (1) preserve the organ, and its function (2) provide an overall survival rate at least equivalent to Access this article online Quick Response Code: $\square$ sis

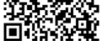

Website: www.sajc.org DOI: 10.4103/2278-330X.136752 that obtained by surgical approaches (3) have a low toxicity profile for a given treatment schedule (4) allow surgical removal in case of recurrent disease as salvage. In an excellent review article published in the current issue of this journal, Dandekar and D'Cruz have discussed the evidence related to chemoradiation and organ preservation in head and neck cancers. ${ }^{[8]}$ Further, critical Indian studies too have been included in this review.

Having a preserved larynx in head and neck cancer can have an impact beyond preservation of the voice. It also can affect the psychological status, performance status and quality of life of patients. Further, it has the potential to lead to better rehabilitation and reintegration of the patient in the general society after the treatment is over. However, both the addition of chemotherapy to RT as well as the use of altered fractionation schedules can increase short-term acute radiation reactions. Even while themselves distressing, these can also lead to pain and distress while swallowing and consequently poor oral intake. Toxicity suffered by the mucosa can result in prolonged low nutritional intake and needs to be guarded against. ${ }^{[9]}$

Use of chemotherapy with altered fractionation too is an active area of interest. However, some trials assessing the role of concurrent chemoradiation with altered fractionation have suggested that acceleration of RT is probably not beneficial in concomitant chemoradiotherapy schedules. ${ }^{[10]}$ Further work in this area is keenly awaited.

As rightly pointed out in the present review in this issue of the journal, the common critique for organ preservation trials remains that the primary endpoint in all the studies was larynx preservation, and the studies were less powered to compare survival. Furthermore, all trials did not use a standard definition of larynx preservation. Some of these concerns should be addressed in the currently running trials which have taken account of these deficits.

Another aspect of organ preservation deserves special mention. Organ preservation does not only means preservation of the anatomical structure. It implies allowing the patient to retain an organ that has reasonably quality functionally post treatment. ${ }^{[1]}$ As such, radiation oncologists need to continuously explore defining and redefining organs at risk and keen on striving for optimal dose thresholds for structures within or adjacent to the target area. This is essential so as to optimally preserve the quality and function of normal tissues. ${ }^{[12]}$

The relative efficacy of the addition of induction chemotherapy to chemoradiotherapy compared with chemoradiotherapy alone for patients with head and neck cancer is unclear. The PARADIGM study is a multicenter open-label Phase III study comparing the use of docetaxel, cisplatin, and fluorouracil induction chemotherapy followed by concurrent chemoradiotherapy with cisplatin-based concurrent chemoradiotherapy alone in patients with locally advanced head and neck cancer. ${ }^{[13]}$ Between August 24, 2004 and December 29, 2008 enrolled 145 patients across 16 sites. Three-year overall survival was $73 \%(95 \% \mathrm{CI}$ : $60-82)$ in the induction therapy, followed by chemoradiotherapy group and $78 \%$ (66-86) in the chemoradiotherapy alone group (HR: $1 \cdot 09,95 \%$ CI: $0 \cdot 59-2 \cdot 03 ; P=0 \cdot 77)$. More patients had febrile neutropenia in the induction chemotherapy, followed by chemoradiotherapy group (16 patients) than in the chemoradiotherapy alone group (one patient). 
A critical question in chemoradiation of head and neck cancer is the use of weekly as against 3 weekly regimes for chemotherapy. While the jury is still out on this, a randomized Phase II/III study was launched in Japan to evaluate the noninferiority of concurrent chemoradiotherapy with weekly cisplatin $\left(40 \mathrm{mg} / \mathrm{m}^{2}\right)$ compared with concurrent chemoradiotherapy with 3 -weekly cisplatin $\left(100 \mathrm{mg} / \mathrm{m}^{2}\right)$ for postoperative high-risk patients with locally advanced squamous cell carcinoma of head and neck. ${ }^{[14]}$ This study began in October 2012, and a total of 260 patients will be accrued from 18 institutions within 5-year. The primary endpoint of the Phase II part is proportion of treatment completion, and that of the Phase III part is overall survival. The secondary endpoints are relapse-free survival, local relapse-free survival, nutrition-support-free survival, nonhospitalized treatment period during permissible treatment period and adverse events.

Some issues related to chemoradiation and organ preservation remain. What are the best approaches of integrating altered fractionation with concurrent chemotherapy? Can salvage organ preservation approaches be used for patients who fail after initial attempted chemoradiation (especially after a long disease free interval)? How can we deal with sites that seem to be benefitting lesser from chemoradiation? How can targeted therapy be fitted in the existing scheme of chemoradiation? Pragmatically designed trials with appropriate end points need to address these issues.

Meanwhile, organ preservation is here to stay, the question is about further improving our strategies and augmenting the existing therapeutic gains.

Anusheel Munshi

Senior Consultant, Radiation Oncology, Fortis Memorial Research Institute, Sector 44, Gurgaon, India Correspondence to: Dr.Anusheel Munshi Email:anusheel8@hotmail.com

\section{References}

1. Lasrado S, Moras K, Pinto GJ, Bhat M, Hegde S, Sathian B, et al. Role of concomitant chemoradiation in locally advanced head and neck cancers. Asian Pac J Cancer Prev 2014; 15:4147-52.

2. Overgaard J, Mohanti BK, Begum N, Ali R, Agarwal JP, Kuddu M, et al. Five versus six fractions of radiotherapy per week for squamous-cell carcinoma of the head and neck (IAEA-ACC study): A randomised, multicentre trial. Lancet Oncol 2010;11:553-60.

3. Minicucci EM, da Silva GN, Salvadori DM. Relationship between head and neck cancer therapy and some genetic endpoints. World J Clin Oncol 2014;5:93-102.

4. Deschler DG, Richmon JD, Khariwala SS, Ferris RL, Wang MB. The "New" Head and Neck Cancer Patient-Young, Nonsmoker, Nondrinker, and HPV Positive: Evaluation. Otolaryngol Head Neck Surg 2014 Jun 12. [Epub ahead of print].

5. Induction chemotherapy plus radiation compared with surgery plus radiation in patients with advanced laryngeal cancer. The Department of Veterans Affairs Laryngeal Cancer Study Group. N Engl J Med 1991;324:1685-90.

6. Lefebvre JL, Chevalier D, Luboinski B, Kirkpatrick A, Collette L, Sahmoud T. Larynx preservation in pyriform sinus cancer: Preliminary results of a European Organization for Research and Treatment of Cancer phase III trial. EORTC Head and Neck Cancer Cooperative Group. J Natl Cancer Inst 1996;88:890-9.

7. Blanchard P, Baujat B, Holostenco V, Bourredjem A, Baey C, Bourhis J, et al. Meta-analysis of chemotherapy in head and neck cancer (MACH-NC): A comprehensive analysis by tumour site. Radiother Oncol 2011;100:33-40.

8. Dandekar M, D'Cruz A. Organ preservation strategies: Review of literature and their applicability in developing nations. South Asian J Cancer 2014;3: 147-50.

9. Munshi A, Pandey MB, Durga T, Pandey KC, Bahadur S, Mohanti BK. Weight loss during radiotherapy for head and neck malignancies: What factors impact it? Nutr Cancer 2003;47:136-40.

10. Bourhis J, Sire C, Graff P, Grégoire V, Maingon P, Calais G, et al. Concomitant chemoradiotherapy versus acceleration of radiotherapy with or without concomitant chemotherapy in locally advanced head and neck carcinoma (GORTEC 99-02): An open-label phase 3 randomised trial. Lancet Oncol 2012;13:145-53.

11. Morato-Galán M, Caminero Cueva MJ, Rodrigo JP, Suárez Nieto C, Núñez-Batalla F. Assessment of vocal quality following treatment of advanced pharyngo-laryngeal carcinoma with a protocol of organ preservation. Acta Otorrinolaringol Esp. 2014 Feb 27. [Epub ahead of print].

12. Munshi A, Agarwal JP. Evolution of radiation oncology: Sharp gun, but a blurred target. J Cancer Res Ther 2010;6:3-4.

13. Haddad R, O'Neill A, Rabinowits G, TishlerR, Khuri F, Adkins D, etal. Induction chemotherapy followed by concurrent chemoradiotherapy (sequential chemoradiotherapy) versus concurrent chemoradiotherapy alone in locally advanced head and neck cancer (PARADIGM): A randomised phase 3 trial. Lancet Oncol 2013; 14:257-64.

14. Kunieda F, Kiyota N, Tahara M, Kodaira T, Hayashi R, Ishikura S, et al. Randomized phase II/III trial of post-operative chemoradiotherapy comparing 3-weekly cisplatin with weekly cisplatin in high-risk patients with squamous cell carcinoma of head and neck: Japan clinical oncology group study (JCOG 1008). Jpn J Clin Oncol 2014 May 19. [Epub ahead of print].

How to cite this article: Munshi A. Head and neck cancers: Safely preserving the talk. South Asian J Cancer 2014;3: 143-4.

Source of Support: Nil. Conflict of Interest: None declared.

Calling all stakeholders in the fight against Cancer

Can-India Conclave

Sunday $30^{\text {th }}$ November 2014

Alongwith $9^{\text {th }}$ SFO Meeting, Gurgaon, NCR

National Conference of Cancer NGOs and Support Groups:

1. Conference

2. Workshops

3. Poster Presentations

4. Display of NGOs activities and products

5. Awards

6. Competition for Cancer Survivors

For further details please contact:

Mail: saarconcology14@gmail.com

Web: www.sfo2014.com

Facebook: SFO2014 